\title{
Fala Osborna u chorego z przypadkową hipotermią - opis przypadku
}

\section{Osborn J wave in patient with accidental hypothermia - case report}

\author{
Olga Wajtryt ${ }^{1}$, Tadeusz M. Zielonka ${ }^{1,2}$, Katarzyna Życińska ${ }^{1,2}$ \\ ${ }^{1}$ Klinika Chorób Wewnętrznych i Metabolicznych Szpitala Czerniakowskiego w Warszawie \\ ${ }^{2}$ Katedra i Zakład Medycyny Rodzinnej Warszawskiego Uniwersytetu Medycznego
}

\section{Streszczenie}

Hipotermia może powodować zaburzenie funkcji wielu narządów. Każde obniżenie ciepłoty ciała wpływa na układ sercowo-naczyniowy. Już przy niewielkim spadku temperatury obserwuje się reakcje kompensacyjne w układzie krążenia, a przy znacznej hipotermii dochodzi do zagrażających życiu zaburzeń rytmu serca. Opisano przypadek znalezionego w śniegu bezdomnego, u którego w przebiegu umiarkowanej hipotermii w zapisie elektrokardiograficznym (EKG) obserwowano napadowe migotanie przedsionków i falę Osborna (tzw. fala J). Po zastosowanym leczeniu i przywróceniu normalnej ciepłoty ciała powrócił rytm zatokowy, a morfologia zespołów QRS była prawidłowa. Na podstawie przypadku i literatury w niniejszym artykule przedstawiono zaburzenia kardiologiczne w hipotermii objawiające się falą Osborna w badaniu EKG.

Słowa kluczowe: przypadkowa hipotermia, fala Osborna, fala J, elektrokardiogram

Folia Cardiologica 2019; 14, 1: 71-74

\section{Wstęp}

Przypadkowa hipotermia to, zgodnie z wytycznymi European Resuscitation Council z 2015 roku, niezamierzone obniżenie temperatury ciała poniżej $35^{\circ} \mathrm{C}$, albo, jeśli jej pomiar jest niemożliwy, ekspozycja na niską temperaturę i poczucie wychłodzenia pacjenta [1]. Wyróżnia się pięć faz hipotermii: I - łagodną $35-32^{\circ} \mathrm{C}$, II - umiarkowaną $32-28^{\circ} \mathrm{C}$, III - ciężką $28-24^{\circ} \mathrm{C}$, IV - zatrzymane krążenia lub stan hipoperfuzji poniżej $24^{\circ} \mathrm{C}$ i V - nieodwracalną poniżej $13,7^{\circ} \mathrm{C}$ [1]. Stanowi ona istotny problem kliniczny w krajach z okresowo niskimi temperaturami [2].

Ze względu na wpływ temperatury na przebieg procesów metabolicznych hipotermia może powodować upośledzenie funkcji wielu narządów, a zwłaszcza układu sercowo-naczyniowego, płuc, nerek, ośrodkowego i obwodowego układu nerwowego [3]. Obniżenie temperatury ciała powoduje zmiany objętości i składu płynu pozakomórkowego oraz wpływa na krzepnięcie krwi [3]. Już przy niewielkim zmniejszeniu ciepłoty ciała obserwuje się reakcje kompensacyjne w układzie krążenia, takie jak tachykardia i zwiększenie pojemności minutowej [2]. W miarę narastania hipotermii wraz z hipoksemią dochodzi do ciężkich zagrażających życiu zaburzeń rytmu serca [2]. Powoduje to różnorodne zmiany w zapisie elektrokardiograficznym (EKG).

Przedstawiono przypadek chorego, u którego w przebiegu przypadkowej hipotermii w zapisie EKG obserwowano falę Osborna (tzw. fala J). Jest ona charakterystyczna w kilku określonych sytuacjach klinicznych, takich jak hipotermia, urazy czaszkowo-mózgowe, a rzadziej hiperkalcemia i komorowe zaburzenia rytmu serca [4]. 


\section{Opis przypadku}

Bezdomny w wieku 63 lat z zespołem zależności alkoholowej został przywieziony do szpitala przez Zespół Pogotowia Ratunkowego po wezwaniu przez Straż Miejską, która znalazła go leżącego na śniegu w okolicy ogródków działkowych, gdzie mieszkał w zimie. Chory negował choroby przewlekłe, alergie, operacje i stosowanie leków. Przy przyjęciu był przytomny (10 pkt. w Glasgow Coma Scale), wyniszczony, zaniedbany higienicznie, ze zmianami troficznymi skóry, licznymi przeczosami i wszawicą. Parametry życiowe były następujące: rytm serca $75 / \mathrm{min}$, ciśnienie tętnicze $90 / 60 \mathrm{~mm} \mathrm{Hg}$, wysycenie tlenem $\left(\mathrm{SaO}_{2}\right) 98 \%$ $\left(\mathrm{FiO}_{2} 0,21\right)$. Stwierdzono także hipotermię z temperaturą ciała $30^{\circ} \mathrm{C}$.

W badaniach laboratoryjnych odnotowano: niedokrwistość (stężenie hemoglobiny 6,7 g/dl), podwyższone parametry stanu zapalnego (stężenie białka C-reaktywnego $10,1 \mathrm{mg} / \mathrm{dl}$ przy normie $0,5 \mathrm{mg} / \mathrm{dl}$ ), cechy rabdomiolizy (aktywność kinazy kreatynowej $3119 \mathrm{j} . / /$ przy normie 26-190 j./I oraz aktywność jej izoenzymu sercowego $207 \mathrm{jm} . / /$ przy normie 2-24 jm./l), podwyższoną aktywność aminotransferaz (asparaginianowej [AspAT, aspartate aminotransferase] $181 \mathrm{j} . / \mathrm{I}$, alaninowej [AIAT, alanine aminotransferase] $100 \mathrm{j} . / \mathrm{l})$, prawidłowe stężenie troponiny $(0,02 \mu \mathrm{g} / \mathrm{l})$. W gazometrii krwi żylnej stwierdzono kwasice (pH 7,187), stężenie mleczanów wynosiło $16 \mathrm{mmol} / \mathrm{l}$, a niedobór lub nadmiar zasad (BE, base excess) - 15,6 mmol/l. $W$ badaniu radiologicznym klatki piersiowej uwidoczniono stan po złamaniu żeber. W tomografii komputerowej (CT, computed tomography) głowy nie opisano istotnych odchyleń. W badaniu ultrasonograficznym (USG) nie obserwowano zmian w narządach jamy brzusznej. W EKG stwierdzono migotanie przedsionków o częstości zespołów QRS 50-90/ min, falę Osborna (tzw. falą J) i ujemne załamki T w odprowadzeniach: II, III i aVF oraz V3-V6 (ryc. 1).

Zastosowano zewnętrzne ogrzewanie fizykalne, resuscytacje płynową, w tym ogrzane płyny, i tlenoterapię. Przetoczono koncentrat krwinek czerwonych. Monitorowano parametry życiowe, obserwując obniżenie ciśnienia tętniczego do 70/50 mm Hg wymagające zwiększenia podaży płynów. Diureza godzinowa początkowo wynosiła poniżej $50 \mathrm{ml} / \mathrm{h}$, a po dożylnym podaniu płynów była prawidłowa. Uzyskano stopniowy wzrost temperatury ciała i po 6 godzinach leczenia przy temperaturze $35^{\circ} \mathrm{C}$ nastąpiła konwersja rytmu do zatokowego. W EKG wykonanym przy temperaturze ciała $36,3^{\circ} \mathrm{C}$ obserwowano bradykardie zatokową, natomiast morfologie zespołów QRS, odcinka ST i załamka T były prawidłowe (ryc. 2). W gazometrii krwi żylnej pH mieściło się w normie, a stężenie mleczanów wynosiło 1,4 mmol/l. W badaniu echokardiograficznym w 2 . dobie pobytu w szpitalu stwierdzono hipokinezę ściany dolnej lewej komory, natomiast wielkość jam serca, grubość
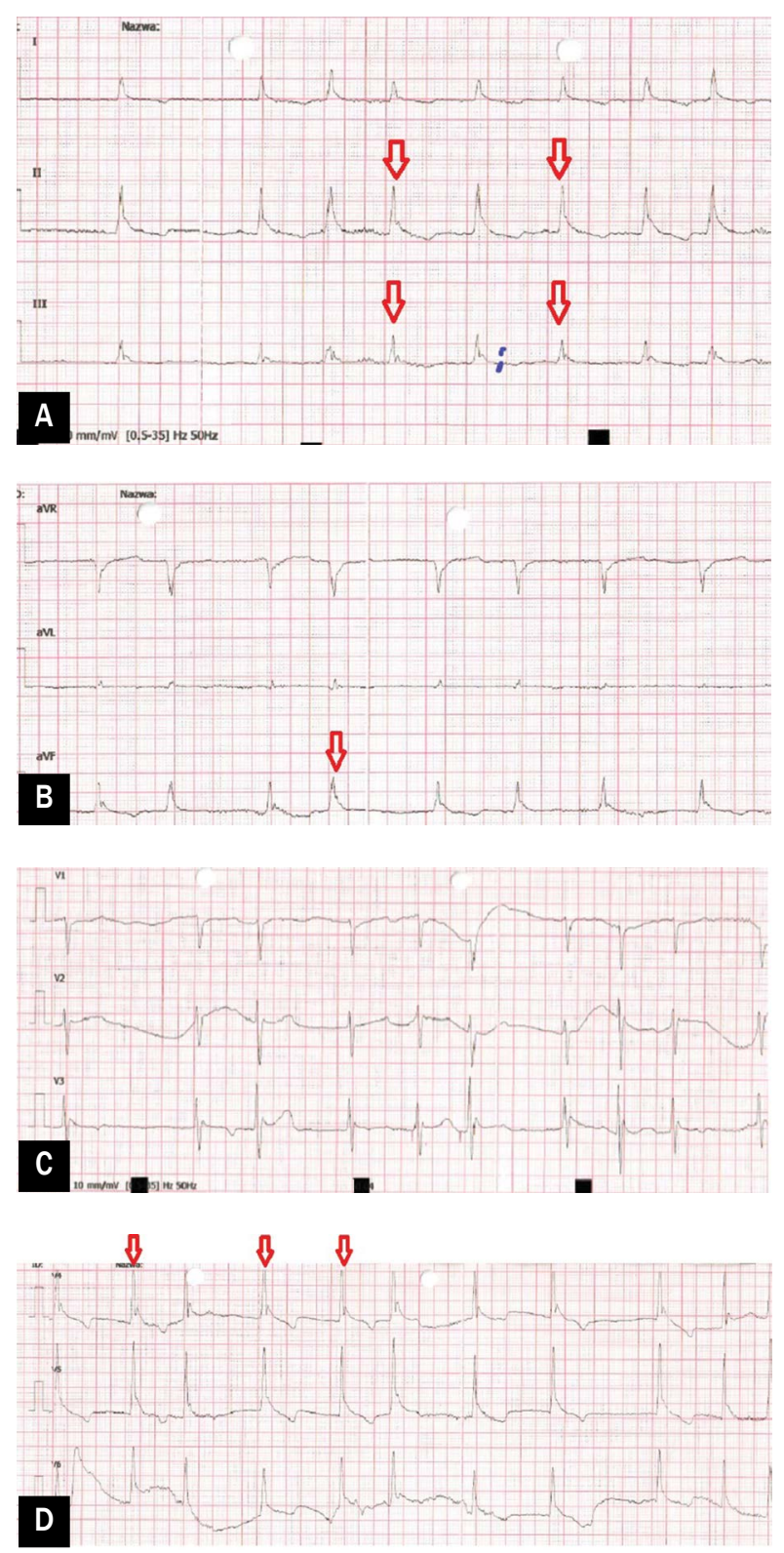

Rycina 1A-D. Badanie elektrokardiograficzne wykonane przy przyjęciu do szpitala (odprowadzenia kończynowe i przedsercowe) migotanie przedsionków o częstości zespołów QRS 50-100/min, fala J, ujemne załamki T w odprowadzeniach ściany dolnej II, III, aVF i odprowadzeniach ściany przednio-bocznej V4-V6

lewej komory, frakcja wyrzutowa i funkcje zastawek były prawidłowe. W kolejnych dniach chory był w dobrym stanie ogólnym; obserwowano jedynie odmrożenia w obrębie III oraz IV palca lewej stopy i po demarkacji zmian zakwalifikowano je do opracowania chirurgicznego. Chory nie wyraził zgody na dalszy pobyt w szpitalu ani diagnostykę i leczenie, ani na pomoc socjalną i umieszczenie w placówce dla osób bezdomnych. Opuścił szpital z zaleceniem dalszego leczenia i kontroli w trybie ambulatoryjnym. 


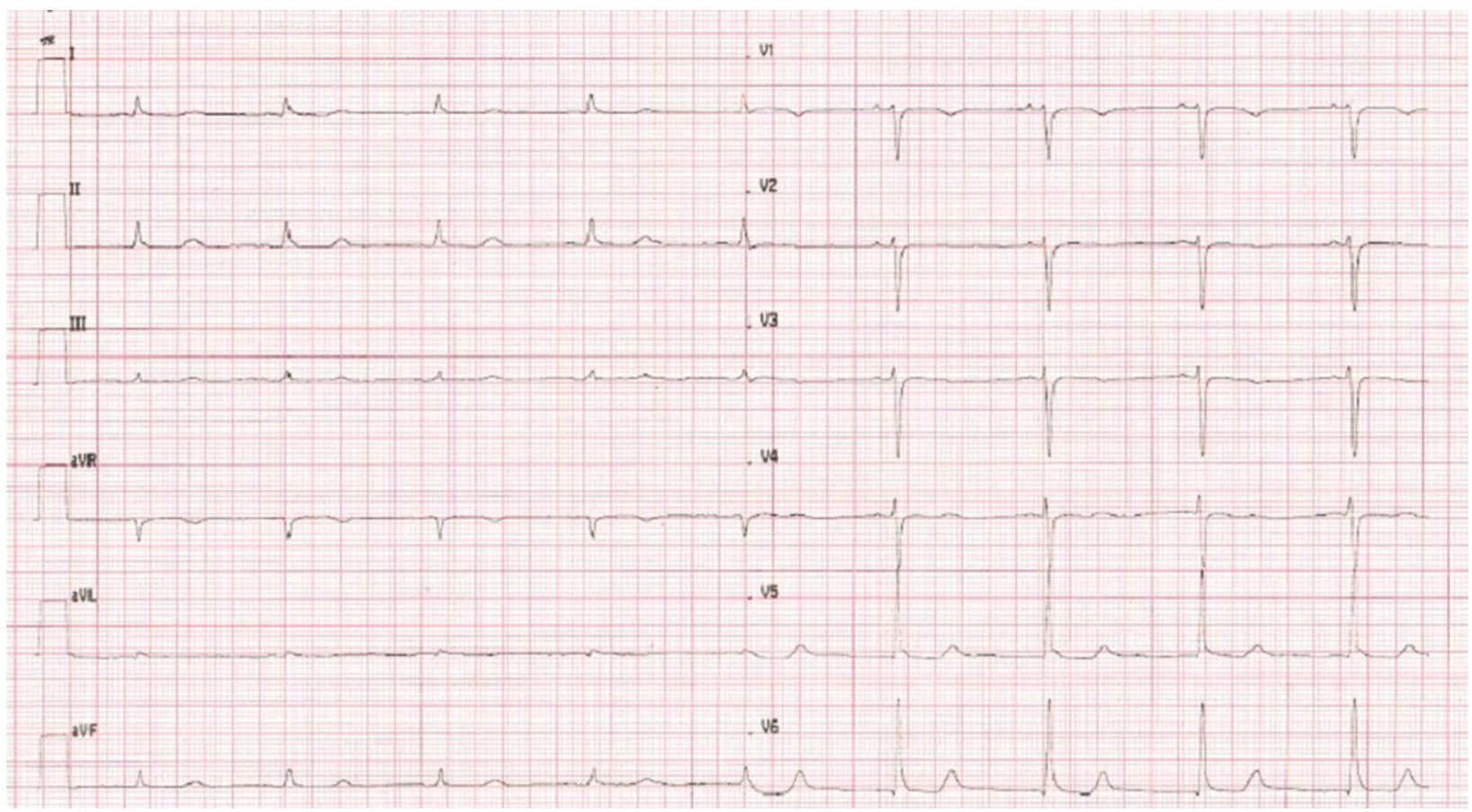

Rycina 2. Badanie elektrokardiograficzne wykonane po 6 godzinach leczenia - rytm zatokowy o częstości 53/min, oś serca prawidłowa, odcinek PQ 120 ms, zespół QRS 100 ms, wydłużone odcinki QT/Qtc 528/512 ms, bez zaburzeń odcinka ST z załamka T

\section{Dyskusja}

Do elektrokardiograficznych objawów hipotermii należą zaburzenia rytmu serca (bradykardia zatokowa, blok przedsionkowo-komorowy, migotanie przedsionków, komorowe zaburzenia rytmu oraz wydłużenie odcinka PR, załamka QRS i odstępu QT [2]. Do tych zaburzeń należy również fala Osborna charakteryzująca się zawęźleniem zespołu QRS w miejscu połączenia załamka R i odcinka ST, który imituje załamek R' [2]. Nazywana jest ona również wielbłądzim garbem, falą J lub rzadziej falą delta [2]. W 1957 roku Joseph Osborn opublikował wyniki badań nad wpływem hipotermii na układy sercowo-naczyniowy i oddechowy [4]. Na podstawie badań eksperymentalnych stwierdził, że fala ta pojawia się w czasie hipotermii, jeśli towarzyszą jej kwasica oraz zaburzenia wentylacji, a zanika po normalizacji temperatury ciała [4]. Mechanizm jej powstania nie jest znany. Hipotezy dotyczą głównie różnic potencjału czynnościowego kardiomiocytów i powstających w hipotermii różnic gradientów między komórkami nasierdzia a wsierdzia, co powoduje zauważalne w EKG zmiany okresu wczesnej repolaryzacji, czyli fazy I potencjału czynnościowego [5]. Fala Osborna nie jest patognomoniczną zmianą dla przypadkowej hipotermii i występuje również w hipotermii terapeutycznej [5], w hiperkalcemii, krwotoku podpajęczynówkowym, urazach czaszkowo-mózgowych, anginie Prinzmetala, migotaniu komór i po nagłym zatrzymaniu krążenia [6]. Najczęściej jest obserwowana w odprowadzeniach znad ścian dolnej i bocznej (V3-V6) [2], a jeśli występuje w odprowadzeniach V1-V2, to wymaga różnicowania z zespołem Brugadów [6].

W opisanych dotychczas przypadkach analizowano korelację amplitudy fali J i temperatury ciała [7], liczbę odprowadzeń, w których obserwowano falę [2], a także związek z zaburzeniami równowagi kwasowo-zasadowej i wymiany gazowej [4] oraz arytmiami komorowymi [5]. Pojedyncze doniesienia nie pozwoliły jednak na stwierdzenie istotnych zależności. Znaczenie prognostyczne fali pozostaje nieznane i wymaga dalszych obserwacji, szczególnie w sytuacji coraz bardziej rozpowszechnionego stosowania hipotermii w terapii różnych schorzeń [5]. Podobnie jak w opisanym przypadku fala Osborna ma charakter przemijający i ustępuje w miarę normalizacji ciepłoty ciała [4]. Świadomość tych zaburzeń elektrokardiograficznych jest pomocna w diagnostyce różnicowej stanów zagrażających życiu, szczególnie na oddziałach ratownictwa medycznego.

\section{Konflikt interesów}

Autorzy nie zgłaszają konfliktu interesu. 


\section{Abstract}

Hypothermia could cause dysfunction of many organs. Any reduction in body temperature affects the circulatory system. Even slightly temperature reduction may result compensatory reactions in the circulatory system, and with significant hypothermia life-threatening arrhythmias are observed. A case of a homeless man, who was found in snow was described, in the course of moderate hypothermia paroxysmal atrial fibrillation and Osborna wave (the so-called J wave) in the electrocardiogram (ECG) was observed. After treatment and warming-up to normal body temperature the sinus rhythm was restored and morphology of the QRS complex was normal. On the basis of the case and literature in this paper cardiological disorders in hypothermia manifested by the Osborn wave in the ECG was presented.

Key words: hypothermia, Osobrn's wave, J-wave, electrocardiogram

Folia Cardiologica 2019; 14, 1: 71-74

\section{Piśmiennictwo}

1. Truhlář A, Deakin CD, Soar J, et al. European Resuscitation Council Guidelines for Resuscitation 2015: section 4. Cardiac arrest in special circumstances. Resuscitation. 2015; 95: 148-201, doi: 10.1016/j. resuscitation.2015.07.017, indexed in Pubmed: 26477412.

2. de Souza D, Riera AR, Bombig MT, et al. Electrocardiographic changes by accidental hypothermia in an urban and a tropical region. J Electrocardiol. 2007; 40(1): 47-52, doi: 10.1016/j.jelectrocard.2006.08.094, indexed in Pubmed: 17027018.

3. Wanscher M, Agersnap L, Ravn J, et al. Outcome of accidental hypothermia with or without circulatory arrest: experience from the Danish Præstø Fjord boating accident. Resuscitation. 2012; 83(9): 1078-1084, doi: 10.1016/j.resuscitation.2012.05.009, indexed in Pubmed: 22634431.
4. Osborn JJ. Experimental hypothermia; respiratory and blood $\mathrm{pH}$ changes in relation to cardiac function. Am J Physiol. 1953; 175(3): 389-398, doi: 10.1152/ajplegacy.1953.175.3.389, indexed in Pubmed: 13114420.

5. Yan GX, Antzelevitch C. Cellular basis for the electrocardiographic J wave. Circulation. 1996; 93(2): 372-379, indexed in Pubmed: 8548912.

6. Maruyama M, Kobayashi $\mathrm{Y}$, Kodani $\mathrm{E}$, et al. Osborn waves: history and significance. Indian Pacing Electrophysiol J. 2004; 4(1): 33-39, indexed in Pubmed: 16943886.

7. Omar HR, Camporesi EM. The correlation between the amplitude of Osborn wave and core body temperature. Eur Heart J Acute Cardiovasc Care. 2015; 4(4): 373-377, doi: 10.1177/2048872614552057, indexed in Pubmed: 25267877. 